\title{
Prognostic Factors of Granulosa Cell Tumors: A Retrospective Study in a Tertiary Care Cancer Centre of Eastern India
}

\author{
Rohini V. Kulkarni ${ }^{1}$ Bhagyalaxmi Nayak ${ }^{1}$ Jita Parija ${ }^{1}$ Janmejaya Mohapatra ${ }^{1}$ \\ Manoranjan Mohapatra ${ }^{1}$ Ashok Padhy ${ }^{1}$ \\ ${ }^{1}$ Department of Gynaecological Oncology, Acharya Harihar Regional \\ Cancer Centre, Cuttack, India \\ Address for correspondence Bhagyalaxmi Nayak, MBBS, MD, PhD, \\ Department of Gynaecological Oncology, Acharya Harihar Regional \\ Cancer Centre, Cuttack, 753007, India \\ South Asian J Cancer 2022;11(1):40-45. \\ (e-mail: blnayak2266@gmail.com).
}

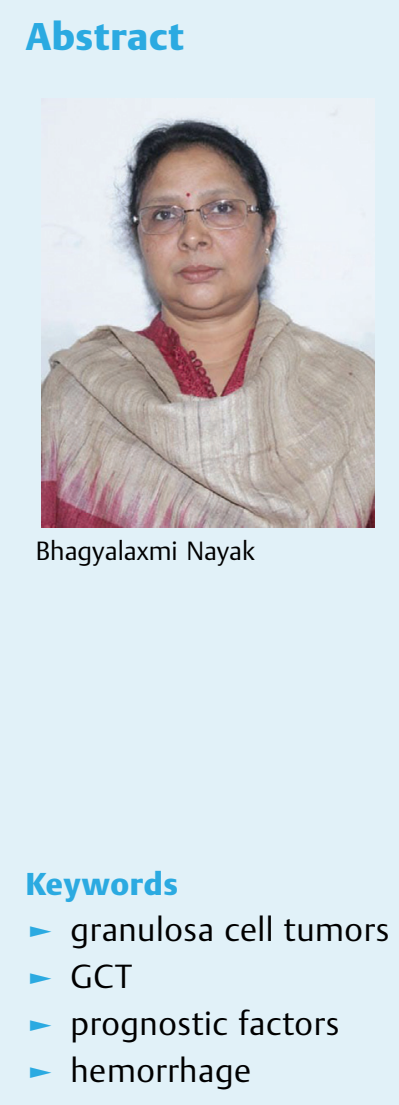

Background and Aims The main objective of this study was to analyze the clinicopathological profile and prognostic factors of granulosa cell tumors (GCT).

Method All the cases of ovarian cancer which were seen at our institute between January 2000 and December 2017 were reviewed. Data were analyzed with failure-free survival (FFS) as the primary end point.

Results GCTs consisted of $2.66 \%$ of all ovarian cancers at our institute. The median age was 43 years. Majority of the patients (62.5\%) were unstaged. Six patients (25\%) had a fertility-preserving procedure. Forty two percent of the patients received adjuvant chemotherapy. Thirty eight percent of the patients developed recurrence. Considering tumor-related prognostic factors, there was a statistically significant decrease in FFS with the presence of hemorrhage $(p=<0.001)$, larger tumors $(p=0.042)$, and juvenile variant $(p=0.002)$. On the contrary, when treatment-related factors were considered, there was no statistically significant improvement in FFS with the performance of lymphadenectomy $(p=0.218)$, omentectomy $(p=0.453)$, fertility sparing surgery $(p=0.152)$, or administration of adjuvant chemotherapy $(p=0.45)$. Conclusion Inherent tumor-related biological factors tend to play a more important role compared with treatment-related factors in GCTs. Hence, the traditional practice of performance of extensive staging procedures and routine adjuvant chemotherapy should be reviewed. Fertility-preserving surgery appears safe to be offered in early stages when desired. Although it is common knowledge that GCTs tend to be hemorrhagic tumors, this factor has not been well recognized as a prognostic indicator till date. Our study sheds some light on this aspect. Since these tumors have a tendency toward late recurrences, a long follow-up is prudent.
DOI https://doi.org/10.1055/s-0041-1740600 ISSN 2278-330X

How to cite this article: Kulkarni RV, Nayak B, Parija J, et al. Prognostic Factors of Granulosa Cell Tumors: A Retrospective Study in a Tertiary Care Cancer Centre of Eastern India South Asian J Cancer 2022;11(1):40-45. (c) 2022. MedIntel Services Pvt Ltd. All rights reserved.

This is an open access article published by Thieme under the terms of the Creative Commons Attribution-NonDerivative-NonCommercial-License, permitting copying and reproduction so long as the original work is given appropriate credit. Contents may not be used for commercial purposes, or adapted, remixed, transformed or built upon. (https://creativecommons.org/licenses/by-nc-nd/ 4.0/)

Thieme Medical and Scientific Publishers Pvt. Ltd., A-12, 2nd Floor, Sector 2, Noida-201301 UP, India 


\section{Introduction}

Granulosa cell tumors (GCTs) of the ovary are classified under sex cord-stromal tumors of the ovary and are the most common among them. They comprise 2 to $5 \%$ of all ovarian malignancies. ${ }^{1}$ Majority patients (57\%) are in stage I at diagnosis and have a relatively favorable outcome with a $90 \%$ survival rate. ${ }^{2}$ However, the outcomes are less favorable as the disease progresses, with survival rates of 50 to $65 \%$ for stage II disease and 17 to $33 \%$ for stage III or IV disease. ${ }^{2}$ There are two types of GCTs-adult variant and the juvenile variant. The peak age of incidence has been reported to be 50 to 55 years. ${ }^{3}$ To this date there are no established risk factors for GCTs, although infertility and infertility treatments have been suggested. ${ }^{3,4}$ These tumors are known to be hormonally active which often produce estrogen and inhibin. Also they have an indolent growth with tendencies to relapse very late. ${ }^{5}$ Considering prognostic factors, other than the FIGO (International Federation of Gynecology and Obstetrics) stage, not many others have been cited in the literature. ${ }^{6}$ In view of rarity of this disease and scarcity of large studies, we undertook this study to analyze the clinicopathological features of GCTs treated at our center with special reference to prognostic factors.

\section{Patients and Methods}

We undertook a retrospective study at our institute (regional cancer center) after acceptance from the institutional ethics committee. We compiled the data between January 2000 and December 2017. We included all the cases of GCTs of the ovary that received any part of the treatment in our hospital in this study period. A detailed review of patient files and records was undertaken. The data were abstracted and analyzed. Clinicopathological profile was studied, treatment practices in our institute evaluated, and an attempt made to outline prognostic factors. Follow-up was once in 3 months for the first year, 6 monthly for the next 4 years, and annually thereafter. Failure-free survival (FFS) was taken as the primary end point for analytical purposes. The Kaplan-Meier method was used in this analysis. The log-rank test was applied in statistical testing.

\section{Results}

There were 900 cases of ovarian carcinoma treated at our center in the study period. Twenty four (2.66\%) cases were of GCT. The median age group of patients was 43 years with a range of 6 to 67 years. Premenopausal patients were majority comprising $54.16 \%$. When parity was considered Majority of the patients were parous (37.5\%). Six patients (25\%) were nulliparous. Most common chief-presenting complaint was abdominal distension (41.6\%), followed by abdominal pain (37.5\%), and abnormal uterine bleeding (20.8\%).

Nine (37.5\%) of these cases underwent a complete staging procedure which included ascitic fluid/peritoneal washings for cytology, thorough assessment of peritoneal cavity with biopsies if needed, total hysterectomy with $b / l$ salpingo- oophorectomy or unilateral adnexectomy (fertility sparing), infragastric omentectomy, and $\mathrm{b} / \mathrm{l}$ pelvic and para aortic lymphadenectomy. Rest 15 cases (62.5\%) did not undergo a comprehensive staging procedure. Eight cases (33.3\%) underwent only a total hysterectomy with b/l salpingo-oophorectomy. Sixteen patients (66.66\%) underwent an omentectomy, while 10 (41.66\%) cases underwent additional lymphadenectomy. Fertility sparing staging procedures were done in six patients $(25 \%)$. Of the nine cases which underwent a complete staging procedure, seven (77.7\%) were stage I, and two cases (22.2\%) were stage IIIC. For one of the cases, staging was not applicable since she was preoperatively wrongly diagnosed as serous papillary carcinoma on fine needle aspiration cytology and had received three cycles of neoadjuvant chemotherapy with paclitaxel and carboplatin.

On histopathology, 21 cases (87.5\%) were diagnosed to be adult GCT, while three (12.5\%) turned out to be of juvenile type. We also assessed the tumor size in these cases. Most of the tumors (66.6\%) were more than $10 \mathrm{~cm}$ in size ranging from 4 to $30 \mathrm{~cm}$. GCTs are known to be hemorrhagic tumors, thirteen $(54.16 \%)$ cases had hemorrhage, including intratumoral and intraperitoneal. None of the cases had lymph node involvement.

In our study adjuvant chemotherapy was given to 10 (41.66\%) patients. The indications for adjuvant chemotherapy included cases of stages IC and higher, and stage IA/IB with tumor size $>10 \mathrm{~cm}$. Four patients who had indications for adjuvant chemotherapy defaulted and were eventually lost to follow-up. One of the patients as elaborated earlier underwent neoadjuvant chemotherapy, surgery followed by adjuvant chemotherapy. This one particular patient received paclitaxel and carboplatin-six cycles in total, while the rest received four cycles of bleomycin, etoposide, and cisplatin.

Our median follow-up was for 30 months ranging between 2 and 72 months. Patients were followed up with serum inhibin B after 2007, and an imaging study was performed based on clinical suspicion or raised inhibin levels. Eleven (45.83\%) remained disease free, nine (37.5\%) had recurrence, and four (16.6\%) were lost to follow-up. Among the six patients who underwent fertility sparing surgeries, four had relapses (66.6\%), three of whom had juvenile GCT. Two (33.3\%) had successful obstetric careers and underwent completion surgery later and remained disease free.

We then analyzed various factors to correlate with recurrence and FFS. There was a statistically significant difference in FFS with respect to tumor-related factors such as presence of hemorrhage (median time of recurrence: 31 vs. 53 months, $p=<0.001$ ), larger tumors of $>10 \mathrm{~cm}$ (median time of recurrence: 43 vs. 62 months, $p=0.042$ ), and juvenile variant (median time of recurrence: 23 vs. 57 months, $p=0.002$ ). But on the contrary, when treatment-related prognostic factors were considered, there was no statistically significant improvement in FFS with the performance of lymphadenectomy (median time of recurrence: 43 vs. 60 months, $p=0.218$ ), omentectomy (median time of recurrence: 50 vs. 55 months, $p=0.453$ ), and fertility sparing surgery (median time of 
Table 1 Prognostic factors

\begin{tabular}{|c|c|c|c|c|c|c|}
\hline Factor & Total No. & Percentage & Recurrences & Percentage & $\begin{array}{l}\text { Median } \\
\text { recurrence }(\mathrm{mo})^{\mathrm{a}}\end{array}$ & $\begin{array}{l}\text { Log-rank } \\
\text { (Mantel-Cox) }\end{array}$ \\
\hline $\begin{array}{l}\text { Hemorrhage, } \\
\text { No. }\end{array}$ & 11 & (11/24) 45.83 & 0 & $(0 / 11) 0$ & 53 & \\
\hline Yes & 13 & (13/24) 54.16 & 9 & (9/13) 69.23 & 31 & $<0.001$ \\
\hline \multicolumn{7}{|l|}{ Size of tumor } \\
\hline$\leq 10 \mathrm{~cm}$ & 8 & (8/24) 33.3 & 1 & $(1 / 8) 12.5$ & 62 & \multirow[t]{2}{*}{0.042} \\
\hline$>10 \mathrm{~cm}$ & 16 & $(16 / 24) 66.6$ & 8 & $(8 / 16) 50$ & 43 & \\
\hline $\begin{array}{l}\text { Histopathology } \\
\text { adult }\end{array}$ & 21 & $(21 / 24) 87.5$ & 6 & $(6 / 21) 28.5$ & 57 & \\
\hline Juvenile & 3 & (3/24) 12.5 & 3 & (3/3) 100 & 23 & 0.002 \\
\hline \multicolumn{7}{|c|}{ Lymphadenectomy } \\
\hline No & 14 & (14/24) 58.33 & 4 & (4/14) 28.57 & 60 & \multirow[t]{2}{*}{0.218} \\
\hline Yes & 10 & (10/24) 41.66 & 5 & $(5 / 10) 50$ & 43 & \\
\hline \multicolumn{7}{|l|}{ Omentectomy } \\
\hline No & 8 & $(8 / 24) 33.33$ & 2 & $(2 / 9) 22.2$ & 55 & \\
\hline Yes & 16 & $(16 / 24) 66.6$ & 7 & (7/9) 77.7 & 50 & 0.453 \\
\hline \multicolumn{7}{|c|}{ Fertility sparing surgery } \\
\hline No & 18 & $(18 / 24) 75$ & 5 & $(5 / 18) 27.77$ & 58 & \\
\hline Yes & 6 & $(6 / 24) 25$ & 4 & $(4 / 6) 66.6$ & 36 & 0.152 \\
\hline \multicolumn{7}{|c|}{ Adjuvant chemotherapy } \\
\hline Defaulters & 4 & (4/24) 16.6 & & & & \multirow[t]{3}{*}{0.45} \\
\hline No & 10 & (10/24) 41.6 & 3 & $(3 / 10) 30$ & 45 & \\
\hline Yes & 10 & (10/24) 41.6 & 6 & $(6 / 10) 60$ & 41 & \\
\hline
\end{tabular}

${ }^{\mathrm{a}}$ Rounded off to the nearest round figure.

recurrence: 36 vs. 58 months, $p=0.152)$. Considering adjuvant treatment, there were four defaulters, 10 who received and 10 who did not require adjuvant chemotherapy. There was no statistically significant difference noted between the two groups (median time of recurrence: 41 vs. 45 months, $p=0.45$ ). All the factors are tabulated in -Table 1 and Kaplan-Meier curves are depicted in -Figs. 1 and 2.

\section{Discussion}

GCT comprises $2.66 \%$ of all ovarian tumors in our institute which was less when compared with data published by Uygun et al ,which was $4.9 \%{ }^{7}$ The median age in our study (43 years) was relatively lesser compared with other studies, which were between 50 and 55 years. ${ }^{6,8,9}$ Our cohort had $62.4 \%$ of the patients who were either unstaged or partially staged without lymphadenectomy, which was in concordance with $60.2 \%$ stated by Sakr et al in a SEER data review of 1,815 patients published in $2016 .^{10}$ When individual stages were considered, we had majority of the patients (29.16\%) in stage I disease, which was in concordance with the review data. Although, histopathologically we had relatively more cases of juvenile GCT (12.5\%) when compared with $1.15 \%$ of them in their data. ${ }^{10}$ Fifty percent of our patients received adjuvant chemotherapy which was comparable $(51.42 \%)$ to that of Auranen et al. ${ }^{6}$ But it was much higher when compared with a study of the role of adjuvant chemotherapy by Meisel et al, ${ }^{9}$ which stood at $8.47 \%$. We had a recurrence rate of $25 \%$ with a median follow-up period of 30 months, which was comparable with 21 and $27 \%$ stated in the previous two studies. 6,9

Due to rarity of the disease, there has been little evidence which pointed out with certainty of any prognostic associations. Only recently, a National Cancer Database study by Seagle et $\mathrm{al}^{8}$ with a cohort of 2,680 patients, a SEER data review of 1,815 patients by Sakr et al, ${ }^{10}$ and a study on the role of adjuvant chemotherapy in GCT by Meisel et $\mathrm{al}^{9}$ have shed some light on this aspect. The three aforementioned studies state the stage of the tumor as a statistically significant prognostic indicator. Our study indicates statistically significant results with respect to FFS when tumor-related factors like presence of hemorrhage $(p=<0.001)$, larger tumors $(p=0.042)$, and juvenile variant $(p=0.002)$ were considered. SEER review also supported this aspect, by revealing that patients with tumors greater than $5 \mathrm{~cm}$ had significantly worse 10-year overall survival (OS; 98.1 vs. $85.1 \%, p<0.05)$. Findings of National Cancer Database are in concordance with this. Although, one of the noteworthy 

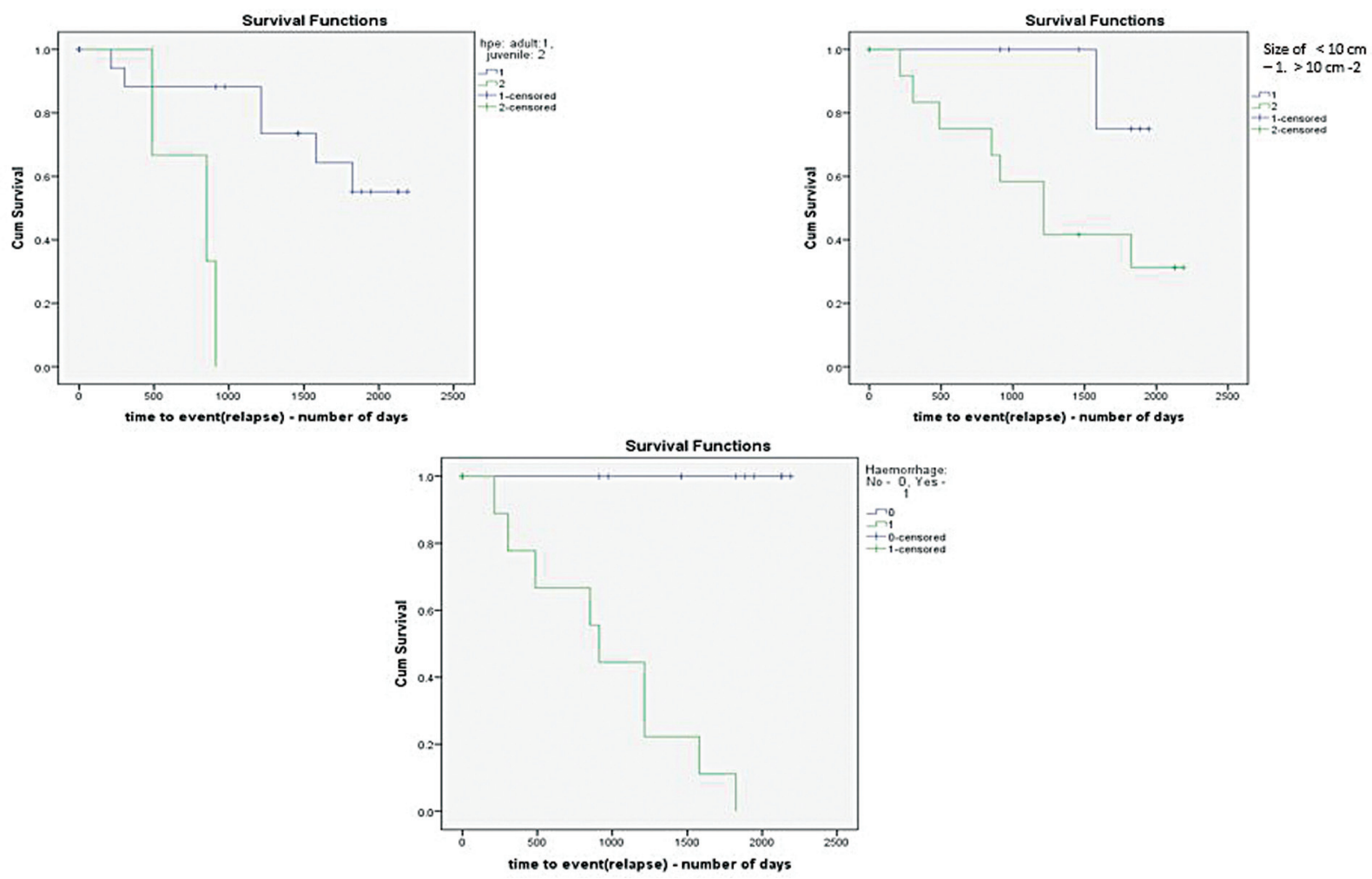

Fig. 1 Kaplan Meir survival curves of tumor related factors.

highlights of our study is that hemorrhagic tumors have a remarkably poorer prognosis, making it a novel new prognostic factor to be studied into in further detail.

The surgical procedure for GCT remains enigmatic. There are a few studies quoted in the literature which recommend against lymphadenectomy ${ }^{11-13}$ in view of low lymph-node positivity rates in these cases, to the tune of $3.1 \% .{ }^{8}$ However, in the recent SEER review data, lymphadenectomy in adult GCT was associated with significantly better OS (89.8 vs. $71.2 \%, p<0.05) .{ }^{10}$ The National Cancer Database study states that lymphadenectomy in GCT is still debatable and that there may be a higher yield in advanced cases. ${ }^{8}$ Lymphadenectomy in our cohort although did not prove to have any significant benefit in improving FFS. Likewise, our figures did not support omentectomy either. Having said that, Seagle et al ${ }^{8}$ have stated that a complete surgical staging defined as hysterectomy with $\mathrm{b} / \mathrm{l}$ salpingo-oophorectomy to have lesser hazard of death. At this point considering fertility sparing procedures, we had a recurrence rate of $66.6 \%$ and a conception rate of $33.3 \%$. Both these figures stood much higher than that quoted in the literature, where the recurrence rate ranged between 9.8 and $27.4 \%$, while the conception rate stood only at $10 \% .{ }^{14}$ With these figures, it is prudent to discuss the risks and benefits of fertility sparing surgeries with patients and offering completion surgery after completion of family.

Likewise there has been a debate about the benefits of adjuvant therapy, guidelines for indications, and the most effective agents. Currently, NCCN (National Comprehensive Cancer Network) recommends either paclitaxel and carbo- platin or bleomycin, etoposide, and cisplatin (malignant germ cell tumor) regimens for stage II to IV GCT. ${ }^{15}$ There are multiple studies which show no clinical benefit from adjuvant chemotherapy, ${ }^{7,11,16-20}$ while certain others have shown survival benefits. ${ }^{6,8-10,21-26}$ Meisel et $\mathrm{al}^{9}$ in turn reported a trend of earlier recurrence of patients who underwent adjuvant therapy. In concordance with the most recent evidence, our study also points toward no FFS benefits with adjuvant chemotherapy.

Late recurrences are a hallmark of GCT, to the tune of 3 to 4 decades after treatment completion has been reported. Literature quotes that approximately $47 \%$ of recurrences occur after 5 years. ${ }^{27}$ Our study reported a median period of recurrence of 40 months (10-60 months).

Shortcomings of this study include an inadequately powered study with reference to small sample size, retrospective nature, and inhomogeneous cohort. Also notable is the relatively short follow-up time considering the tendency of these tumors to very late recurrences.

\section{Conclusion}

Inherent tumor-related biological factors tend to play a more important role compared with treatment-related factors in GCTs. Hence, the traditional practice of performance of extensive staging procedures and routine adjuvant chemotherapy should be reviewed. Fertility preserving surgery appears safe to be offered in early stages when desired. Although it is common knowledge that GCTs tend to be hemorrhagic tumors, this factor has not been well 

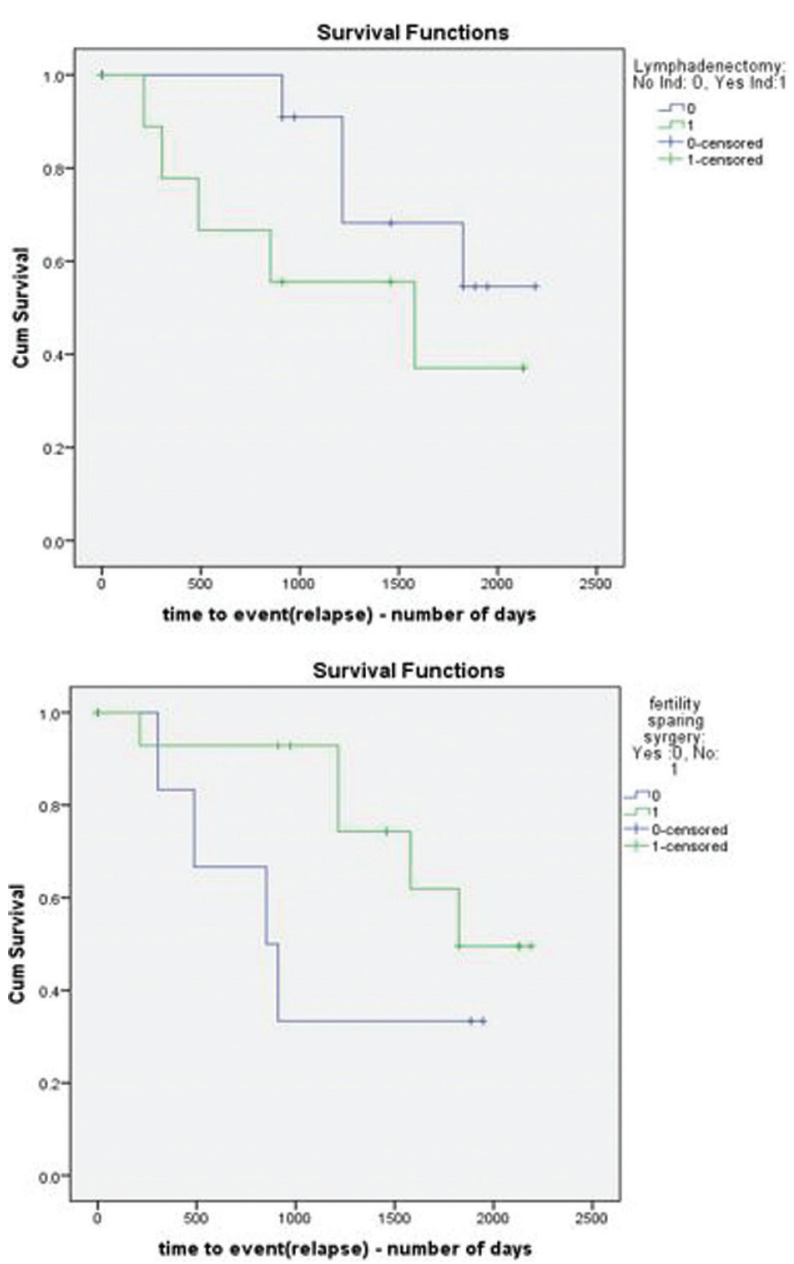

Fig. 2 Kaplan Meir survival curves of treatment related factors.

recognized as a prognostic indicator till date. Our study sheds some light on this aspect. Since these tumors have a tendency toward late recurrences, a long follow-up is prudent.

Source of Support

None.

\section{Conflict of Interest}

None.

\section{Acknowledgments}

We thank Prof. Sushil Kumar Giri for his unrelenting academic and moral support and Dr. Bhavya for lending her expertise on statistical analysis.

\section{References}

1 Quirk JT, Natarajan N. Ovarian cancer incidence in the United States, 1992-1999. Gynecol Oncol 2005;97(02): 519-523

2 Schumer ST, Cannistra SA. Granulosa cell tumor of the ovary. J Clin Oncol 2003;21(06):1180-1189

3 Willemsen W, Kruitwagen R, Bastiaans B, Hanselaar T, Rolland R. Ovarian stimulation and granulosa-cell tumour. Lancet 1993;341 (8851):986-988
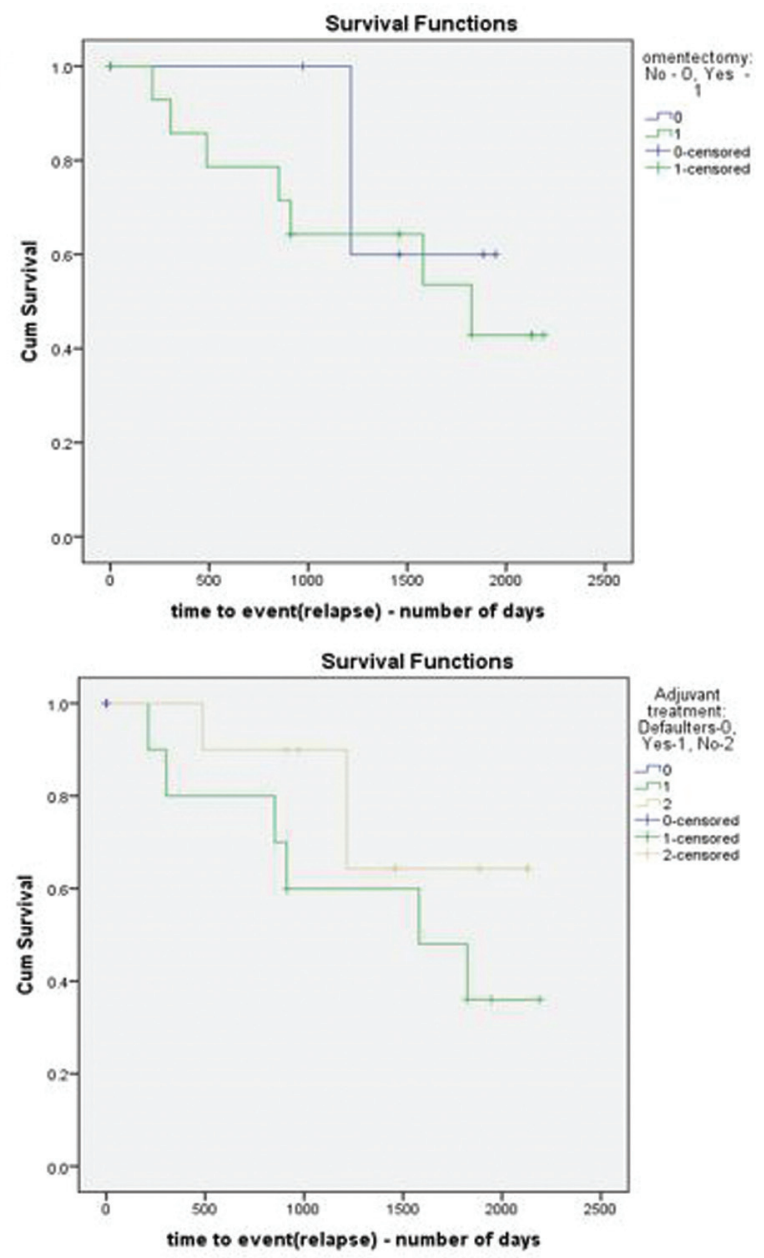

4 Unkila-Kallio L, Tiitinen A, Wahlström T, Lehtovirta P, Leminen A. Reproductive features in women developing ovarian granulosa cell tumour at a fertile age. Hum Reprod 2000;15(03):589-593

5 East N, Alobaid A, Goffin F, Ouallouche K, Gauthier P. Granulosa cell tumour: a recurrence 40 years after initial diagnosis. J Obstet Gynaecol Can 2005;27(04):363-364

6 Auranen A, Sundström J, Ijäs J, Grénman S. Prognostic factors of ovarian granulosa cell tumor: a study of 35 patients and review of the literature. Int J Gynecol Cancer 2007;17(05):1011-1018

7 Uygun K, Aydiner A, Saip P, et al. Granulosa cell tumor of the ovary: retrospective analysis of 45 cases. Am J Clin Oncol 2003;26 (05):517-521

8 Seagle BLAnn P, Butler S, Shahabi S. Ovarian granulosa cell tumor: a National Cancer Database study. Gynecol Oncol 2017;146(02): 285-291

9 Meisel JL, Hyman DM, Jotwani A, et al. The role of systemic chemotherapy in the management of granulosa cell tumors. Gynecol Oncol 2015;136(03):505-511

10 Sakr SAl-Wahab Z, Abdulfatah E, et al. Granulosa cell tumors: A SEER data review of prognostic parameters in 1815 patients. Gynecol Oncol 2017;145(Suppl 1):127

11 Park JY, Jin KL, Kim DY, et al. Surgical staging and adjuvant chemotherapy in the management of patients with adult granulosa cell tumors of the ovary. Gynecol Oncol 2012;125(01):80-86

12 Thrall MM, Paley P, Pizer E, Garcia R, Goff BA. Patterns of spread and recurrence of sex cord-stromal tumors of the ovary. Gynecol Oncol 2011;122(02):242-245

13 Brown J, Sood AK, Deavers MT, Milojevic L, Gershenson DM. Patterns of metastasis in sex cord-stromal tumors of the ovary: 
can routine staging lymphadenectomy be omitted? Gynecol Oncol 2009;113(01):86-90

14 Iavazzo C, Gkegkes ID, Vrachnis N. Fertility sparing management and pregnancy in patients with granulosa cell tumour of the ovaries. J Obstet Gynaecol 2015;35(04):331-335

15 National Comprehensive Cancer Network. Ovarian cancer (version 2 2018). Accessed on July 20, 2018 at: http://www.nccn.org/professionals/physician_gls/pdf/ovarian.pdf

16 Sigismondi C, Gadducci A, Lorusso D, et al. Ovarian Sertoli-Leydig cell tumors: a retrospective MITO study. Gynecol Oncol 2012;125 (03):673-676

17 Shavit T, Bruchim I, Ben-Harim Z, Fishman A. Successful response to docetaxel treatment in recurrent ovarian granulosa cell tumor: a case report. Eur J Gynaecol Oncol 2012;33(04):419-420

18 Savage P, Constenla D, Fisher C, et al. Granulosa cell tumours of the ovary: demographics, survival and the management of advanced disease. Clin Oncol (R Coll Radiol) 1998;10(04):242-245

19 Li W, Wu X, Fang C, Yao J, Guo Y, Zhang S. Prognostic factors in adult granulosa cell tumor of the ovary. Saudi Med J 2009;30(02): 247-252

20 Chiara S, Merlini L, Campora E, et al. Cisplatin-based chemotherapy in recurrent or high risk ovarian granulosa-cell tumor patients. Eur J Gynaecol Oncol 1993;14(04):314-317
21 Al-Badawi IA, Brasher PM, Ghatage P, Nation JG, Schepansky A, Stuart GC. Postoperative chemotherapy in advanced ovarian granulosa cell tumors. Int J Gynecol Cancer 2002;12(01): 119-123

22 Zanagnolo V, Pasinetti B, Sartori E. Clinical review of 63 cases of sex cord stromal tumors. Eur J Gynaecol Oncol 2004;25(04): 431-438

23 Gurumurthy M, Bryant A, Shanbhag S. Effectiveness of different treatment modalities for the management of adult-onset granulosa cell tumours of the ovary (primary and recurrent). Cochrane Database Syst Rev 2014;4(04):CD006912

24 Sun HD, Lin H, Jao MS, et al. A long-term follow-up study of 176 cases with adult-type ovarian granulosa cell tumors. Gynecol Oncol 2012;124(02):244-249

25 Lee IH, Choi CH, Hong DG, et al. Clinicopathologic characteristics of granulosa cell tumors of the ovary: a multicenter retrospective study. J Gynecol Oncol 2011;22(03):188-195

26 Chan JK, Zhang M, Kaleb V, et al. Prognostic factors responsible for survival in sex cord stromal tumors of the ovary-a multivariate analysis. Gynecol Oncol 2005;96(01):204-209

27 Mangili G, Ottolina J, Gadducci A, et al. Long-term follow-up is crucial after treatment for granulosa cell tumours of the ovary. Br J Cancer 2013;109(01):29-34 